\title{
Comparison of Acceleration and Impact Stress as Possible Loading Factors in Phonation: A Computer Modeling Study
}

\author{
Jaromír Horáček ${ }^{a}$ Anne-Maria Laukkanen ${ }^{d}$ Petr Šidlof ${ }^{b}$ Peter Murphy ${ }^{\mathrm{e}}$ \\ Jan G. Švec ${ }^{c}$ \\ anstitute of Thermomechanics, Academy of Sciences of the Czech Republic, Prague, ${ }^{b}$ Faculty of Mechatronics, \\ Technical University of Liberec, Liberec, and 'Laboratory of Biophysics, Department of Experimental \\ Physics, Faculty of Science, Palacký University Olomouc, Olomouc, Czech Republic; ${ }^{d}$ Department of Speech \\ Communication and Voice Research, University of Tampere, Tampere, Finland; e Department of Electronic and \\ Computer Engineering, University of Limerick, Limerick, Ireland
}

\section{Key Words}

Biomechanics of voice modeling $\cdot$ Fundamental frequency $\cdot$ Phonation type $\cdot$ Gender differences in voice $\cdot$ Vocal nodules

\begin{abstract}
Impact stress (the impact force divided by the contact area of the vocal folds) has been suspected to be the main traumatizing mechanism in voice production, and the main cause of vocal fold nodules. However, there are also other factors, such as the repetitive acceleration and deceleration, which may traumatize the vocal fold tissues. Using an aeroelastic model of voice production, the present study quantifies the acceleration and impact stress values in relation to lung pressure, fundamental frequency (FO) and prephonatory glottal half-width. Both impact stress and acceleration were found to increase with lung pressure. Compared to impact stress, acceleration was less dependent on prephonatory glottal width and, thus, on voice production type. Maximum acceleration values were about 5-10 times greater for high FO (approx. $400 \mathrm{~Hz}$ ) compared to low FO (approx. 100 $\mathrm{Hz}$ ), whereas maximum impact stress remained nearly unchanged. This suggests that acceleration, i.e. the inertia forc-
\end{abstract}

es, may present at high FO a greater load for the vocal folds, and in addition to the collision forces may contribute to the fact that females develop vocal fold nodules and other vocal fold traumas more frequently than males.

Copyright $\odot 2009$ S. Karger AG, Basel

\section{Introduction}

About one third of the labor force relies on the voice [1]. A well-functioning voice, however, is not straightforward, but voice problems are very common. Women are reported to have more voice problems than men [2]. The higher prevalence of voice problems in females has been explained for example through higher fundamental frequency (F0) [3], which naturally implies that whatever loading mechanisms are related to vocal fold vibration, the number of their repeated occurrence for a specific time period is about double in females compared to males. Gender-related differences in the laryngeal structure [4], in vocal fold tissue and molecular structure [5] and hormonal factors $[6,7]$ could also contribute to the higher prevalence of voice problems in females [6-8].

Jaromír Horáček, Ing., DrSc

Institute of Thermomechanics

Academy of Sciences of the Czech Republic, Dolejškova 5

CZ-182 00 Prague 8 (Czech Republic)

Tel. +420286890 383, Fax +420286584695, E-Mail jaromirh@it.cas.cz 
Vocal fold vibration includes several loading mechanisms. The vocal fold tissue can be loaded with a normal stress (either tensile or compressive) and with a shear stress (applied in a direction other than perpendicular to the tissue). When the glottis closes, an impact takes place and the vocal fold tissue gets compressed near the contact. In general, a complicated three-dimensional loading by both the normal and shear stresses occurs in the tissue immediately after the impact [9-12]. Acceleration and deceleration of the vocal fold tissue, i.e. the rapidness in changes of the vocal fold velocity, induce normal and shear stresses as well. How detrimental the stress is for the tissue depends not only on the magnitude of the stress, but also on its rate of occurrence and on the endurance of the tissue. Furthermore, the tissue structure (i.e. the direction of the tissue fibers) affects its vulnerability to the type of stress applied.

Titze [8] has estimated the magnitude of various stresses related to vocal fold vibration and discussed their potential detrimental effects. He considered the impact stress (IS) as the most detrimental stress for the vocal fold tissue.

IS has been reported to increase with F0, sound pressure level (SPL) and adduction (increased adduction implies a smaller prephonatory glottal width) [13]. This appears in line with clinical observations and experimental results showing the voice complaints to be related to higher F0, SPL and a more hyperfunctional type of voice production $[3,14]$.

Vocal fold nodules appear in the upper part of the vocal folds [5], at the middle of the musculomembranous portion where the amplitude of vibration is greatest [15]. This suggests that the collision forces are an important cause of these traumas. The nodules appear within the striking zone $[16,17]$ below the superficial layer of the vocal folds. This raises the question as to why the IS damages the deeper layer of the colliding tissue while leaving the uppermost layer intact. A possible explanation may be due to a faster recovery in the uppermost layer or, alternatively, the fact that the maximum shear stress, which can be crucial for tissue failure, is located underneath the contact surface, as known from the classical Hertz contact theory [18]. This shear stress is linearly correlated with IS.

On the other hand, vascular lesions (ectasias and varices [17]) appear on the superior surface of the vocal folds, where no collision occurs. Since the vocal fold tissue is nearly incompressible material, the impact loading may result in some bulging of the superior vocal fold surface. This bulging, however, does not seem to be sufficient to explain the appearance of vascular lesions. Instead, other possible traumatizing mechanisms need to be considered. One possibility may be the rapid acceleration and deceleration of the tissue occurring during vocal fold vibration [19]. Rapid deceleration is expected during glottal closing (at the instant of collision), while high acceleration is expected during the opening phase.

The vocal folds move rapidly not only in the transverse direction, but also in the vertical direction $[15,20,47]$. On the basis of the picture sequence by Hirano [20], it is possible to derive that in chest register the extent of vertical movement of the vocal fold approximately equals that of horizontal movement (with the amplitudes up to $1.5 \mathrm{~mm}$ ) [21]. Based on high-speed filming of an excised canine hemilarynx, Berry et al. [15] showed trajectories of up to $4 \mathrm{~mm}$ lateral and $1.5 \mathrm{~mm}$ vertical rolling movements in the upper part of the vocal fold. In excised human larynges, the displacement ranges were measured up to $2.0 \mathrm{~mm}$ laterally and $1.2 \mathrm{~mm}$ vertically [47]. These upward and downward as well as rolling movements would imply at least vertical pulling of the tissue including the influence of acceleration and deceleration.

Based on measurements of vocal fold contact stress and amplitude of vibration, Titze [22] estimated acceleration $(A C)$ values for $F 0$ from 100 to $300 \mathrm{~Hz}$. These $A C$ values (about $500-5,000 \mathrm{~m} / \mathrm{s}^{2}$ ) exceed the safety limits for tissue vibrations [23]. Jiang et al. [24] estimated IS and $A C$ values for excised canine larynges using photoglottography (PGG). Schubert et al. [25], Larsson and Hertegård [26], Schade et al. [27], Doellinger et al. [28], Doellinger and Berry [44] and Boessenecker et al. [47] measured movement of the human vocal folds using high-speed filming on the basis of which it is possible to derive $A C$ values. However, experimental investigation of $I S$ and $A C$ is challenging for various reasons. Problems in the use of excised larynges in voice studies include flabbiness of the tissue and nonfunctioning of the thyroarytenoid muscle. Differences in the laryngeal and vocal fold tissue structure between species limit the applicability of the results obtained; for example with the use of canine larynges. IS is difficult to measure in humans; for example, transducer placement between the vocal folds in vivo is problematic. Measurement of $A C$ on the basis of PGG and highspeed filming is affected by the limitations and shortcomings of the methods: (a) reflections and leakage of illumination affects PGG, (b) in filming the glottis from above, the movements of the lower parts of the vocal folds cannot always be reliably registered, and (c) in most cases the speed of the high-speed filming is not sufficiently high. Moreover, the fact that human subjects tend to si- 
Table 1. Vocal fold geometry: the input data used in numerical simulations

\begin{tabular}{|c|c|c|c|c|c|}
\hline & $\begin{array}{l}\text { Thickness } \\
L, \mathrm{~mm}\end{array}$ & $\begin{array}{l}\text { Length } \\
h, \mathrm{~mm}\end{array}$ & $\begin{array}{l}\text { Width } \\
D, \mathrm{~mm}\end{array}$ & $\begin{array}{l}\text { Vocal fold shape } \\
a(x), \mathrm{m}\end{array}$ & $\begin{array}{l}\text { Total mass } \\
m, \mathrm{~g}\end{array}$ \\
\hline \multicolumn{6}{|l|}{ Test 1} \\
\hline Intermediate bulging $; F 0=100$ and $400 \mathrm{~Hz}$ & $6.80^{\mathrm{a}}$ & $10^{\mathrm{a}}$ & $5.4^{\mathrm{a}}$ & $1.858 x-159.86 x^{2}$ & 0.26731 \\
\hline \multicolumn{6}{|l|}{ Test 2} \\
\hline Bass SFF; $F 0=91 \mathrm{~Hz}$ & $5.50^{\mathrm{b}}$ & $14.3^{\mathrm{c}}$ & $4.9^{\mathrm{c}}$ & $2.084 x-221.67 x^{2}$ & 0.28059 \\
\hline Bass $2 \times \mathrm{SFF} ; F 0=182 \mathrm{~Hz}$ & $4.27^{\mathrm{b}}$ & $14.7^{\mathrm{c}}$ & $5.3^{\mathrm{c}}$ & $2.903 x-397.48 x^{2}$ & 0.29954 \\
\hline Soprano SFF; F0 = $189 \mathrm{~Hz}$ & $3.96^{\mathrm{b}}$ & $10.7^{\mathrm{c}}$ & $3.8^{\mathrm{c}}$ & $2.247 x-332.05 x^{2}$ & 0.11715 \\
\hline Soprano $2 \times \mathrm{SFF} ; F 0=378 \mathrm{~Hz}$ & $3.14^{\mathrm{b}}$ & $11.2^{\mathrm{c}}$ & $3.1^{\mathrm{c}}$ & $2.309 x-429.98 x^{2}$ & 0.07940 \\
\hline
\end{tabular}

multaneously vary different vocal parameters (e.g. F0, $S P L$, adduction, lung pressure) limits our ability to draw specific conclusions on the true relationships between the vocal parameters studied and the forces related to vocal fold vibration.

The progress in vocal fold oscillation modeling in the last few years has allowed employing computer models for studying independently the effects of different parameters, including the $I S$ and $A C$. The finite element models have provided insight into the mechanism of impact stress [9-12], but they suffer from too much complexity and the lack of accurate information on tissue properties. An alternative simpler solution has been offered by incorporating the Hertz model of impact forces into a simple vocal fold aeroelastic model [29]. The Hertz model allows calculating the impact force from the mathematically exact shape and elastic properties of the vocal fold, and from the impact velocity resulting from the aerodynamic forces acting on the self-oscillating vocal folds. Pilot results on the impact stress using this model were reported in the study of Horáček et al. [30]. The obtained magnitudes of IS were within the limits reported in the literature. IS increased with lung pressure almost linearly after phonation threshold, but reached a plateau when the limit of maximum glottal opening was reached. In line with experimental results [13], IS increased with SPL, suggesting that loud phonation implies higher vocal fold loading.

This study exploits the aeroelastic model [29] for determining the acceleration and impact stress dependence on lung pressure $\left(P_{\text {lung }}\right)$, fundamental frequency and prephonatory glottal width. A modification to the previous version of the model [30] has also been made here: the length and width values of male and female vocal folds at different pitch levels measured by Larsson and Hertegård [31] have been applied and consequently the shape of the vocal fold in the model has also been changed. The vocal fold thickness (the vertical dimension) has been estimated from the empirical formulas for males and females according to Titze et al. [19].

\section{Method}

An aeroelastic three-mass computer model employing a Hertz model of impact forces during vocal fold collision was used for inspection of simultaneous impact stress and acceleration variation in relation to typical quantities encountered in speech modeling. For a description of the model, see Horáček et al. [29].

The model was tested $[30,32]$ and found to yield values of the important voice parameters (e.g. phonation threshold pressure, $P_{\text {th }}$, ratios of the glottal area waveform, and their relations to lung pressure, $P_{\text {lung }}, F O$ and $S P L$ at the supraglottal end of the glottis, $\left.S P L_{\text {source}}\right)$ that correspond well with those found in living subjects and in excised larynges.

The model is based on a two-degrees-of-freedom dynamic system allowing rotation and translation of the vocal-fold-shaped element vibrating on two springs and dampers. Symmetrical vocal fold oscillations are assumed, and thus only half of the glottis is modeled. Acoustic-mechanical interactions with the vocal tract and subglottic spaces are not modeled. Self-oscillations are excited by nonlinear aerodynamic forces resulting from fluid-structure interaction. A parabolic shape function $a(x)$ approximates the geometry of the vocal folds and defines the bulging and the curvature of the impacting surfaces at the point of contact. An inviscid incompressible airflow is considered with the air density $\rho=1.2 \mathrm{~kg} / \mathrm{m}^{3}$. Three equivalent masses $m_{1}, m_{2}$ and $m_{3}$ were calculated from the vocal fold tissue density $\rho_{h}=1,020 \mathrm{~kg} / \mathrm{m}^{3}$, from the vocal fold geometry given by the function $a(x)=a_{1} x+a_{2} x^{2}$ for $x \in\langle 0, L\rangle$ and from the dimensions: thickness $L$, width (depth) $D$ and length $h$.

Table 1 shows the values used in simulations for vocal fold sizes at different fundamental frequencies. In test 1 , the shape that corresponds to the geometry of the vocal fold with an intermediate bulging' [33] was taken into account. In test 2 , the size values reported by Larsson and Hertegård [31] and Titze et al. [19] were used for the mean speaking fundamental frequencies (SFF) of so- 
Fig. 1. Animation of the vocal fold motion during one oscillation cycle $(F 0 \cong 100 \mathrm{~Hz}$, $\left.P_{\text {lung }}=213.7 \mathrm{~Pa}, g_{0}=0.2 \mathrm{~mm}\right)$.

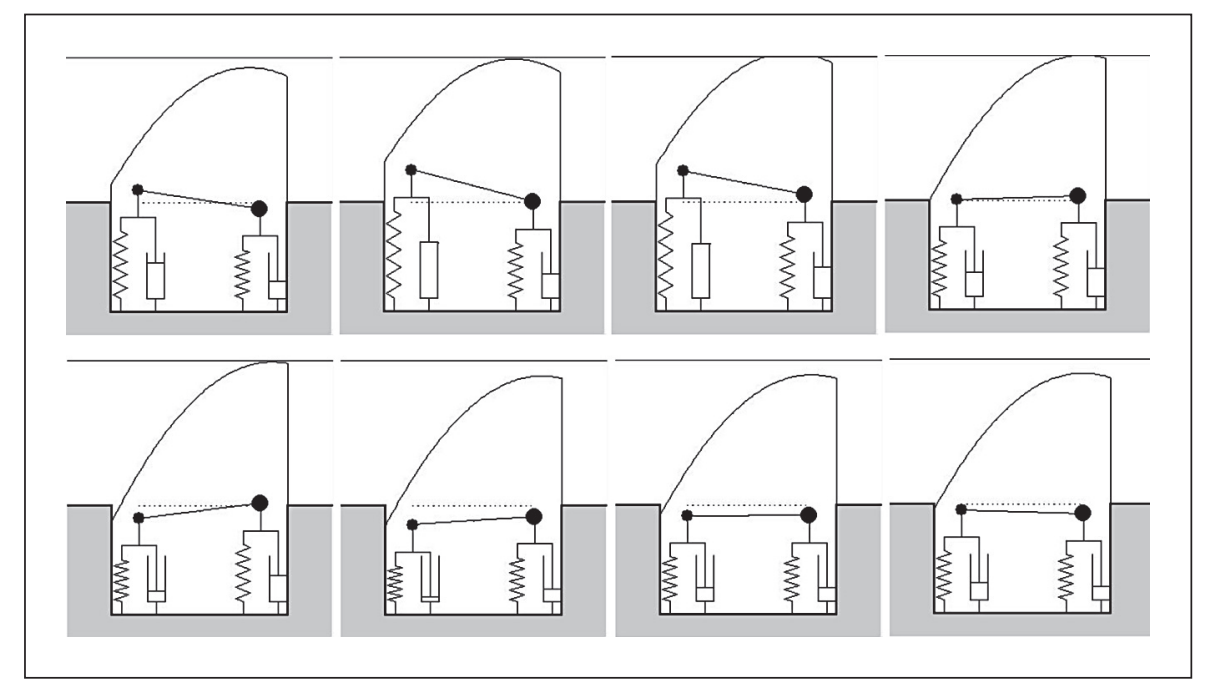

prano and bass and for the mean fundamental frequencies one octave higher in pitch $(2 \times \mathrm{SFF})$. The vocal fold shape function $a(x)$ was rescaled according to the $L$ and $D$ dimensions.

The collision impact Hertz force is given as $F_{H}(t)=k_{H} \delta(t)^{3 / 2}$, where $k_{H}=4 / 3 \sqrt{r} E /\left(1-v^{2}\right)$ is the contact stiffness and $\delta(t)$ is the penetration of the vocal fold through the symmetry axis during collision (resulting from the airflow-induced self-oscillations of the model); $r=1 /\left(\partial^{2} a / \partial x^{2}\right)=$ constant is the radius of the curvature of the vocal fold model at the contact point. A Young's modulus of $E=8,000 \mathrm{~Pa}$ and Poisson number of $v=0.4$ were considered for the vocal fold tissue $[34,35]$. All these input parameters were kept constant during the simulations.

The impact stress IS is the compressive stress on the contact surface defined as the impact force $F_{\mathrm{H}}$ divided by the contact area of the vocal folds. The maximum IS in the model was calculated as the maximum value during one oscillation period [29]:

$$
I S=\frac{3}{2} \frac{F_{H, \max }}{\pi S_{\max }^{2}}
$$

where

$$
\boldsymbol{S}_{\max }=\sqrt[3]{\frac{3}{4}} r \frac{\left(1-\nu^{2}\right)}{E} F_{H, \max }
$$

is the radius (half-width in two dimensions) of the maximum contact area and $F_{\mathrm{H} \text {, max }}$ is the maximum impact force.

Before starting the numerical simulations, a tuning procedure $[29,36]$ was used to adjust the stiffness of the supporting springs in order to approximate the desired fundamental frequency Fo. This was done by setting the natural frequencies of the dynamic system in vacuo as $f_{1}=F 0, f_{2}=F 0+5 \mathrm{~Hz}$. The damping was adjusted in order to approximate 3-dB half-power bandwidths of both resonances $\Delta f_{1}=23 \mathrm{~Hz}$ and $\Delta f_{2}=29 \mathrm{~Hz}$ according to in vivo measurements in humans [37].

\section{Numerical Simulations for Quantifying Impact Stress and} Acceleration

The following procedure was adopted in the modeling for both test 1 and test 2 cases specified in table 1 . Values $P_{\text {lung }}<$
$3 \mathrm{kPa}$ and $Q<0.8 \mathrm{l} / \mathrm{s}$ (corresponding to values found in normal phonation in humans $[20,38,39]$ ) were considered in the simulations for the lung pressure and the mean glottal flow rate, respectively. The controlled parameter was lung pressure $P_{\text {lung, which }}$ was varied from the phonation threshold pressure, $P_{\text {th }}$, up to $3 \mathrm{kPa}$ or up to a value which exceeded the maximum flow rate of $Q=0.8 \mathrm{l} / \mathrm{s}$. In a number of cases studied, the upper value for $P_{\text {lung }}$ was limited by the so-called phonation instability threshold pressure [40], beyond which the oscillations became irregular (chaotic or quasi-periodic). An example of the motion of the vocalfold-shaped body during one period of self-oscillations is shown in figure 1.

The following parameters were automatically calculated online from the output quantities simulated in the time domain:

(a) Maximum positive acceleration $A C_{+}$, maximum negative acceleration $A C_{-}$and absolute values $|A C|=\max \left(A C_{+}, A C_{-}\right)$were computed numerically as the second derivative $\partial^{2} w_{2} / \partial t^{2}$ of the simulated displacement $w_{2}(t)$ of the second (upper) mass $m_{2}$ during an oscillation cycle, because the upper mass level corresponds approximately to the position where the nodules usually appear.

(b) Maximum IS during an oscillation cycle was calculated using the equation 1 .

\section{Test 1}

Fundamental frequency F0 values were set at 100 and $400 \mathrm{~Hz}$ since these values correspond to those measured in normal and loud speech $[39,41]$. The prephonatory glottal half-width was varied in the range $g_{0}=0.2-0.5 \mathrm{~mm}$ reported in the literature [13, 42].

\section{Test 2}

Mean F0 values obtained by Larsson and Hertegård [31] for the speaking pitch of bass and soprano singers as well as pitch values one octave higher than the speaking pitch ( $2 \mathrm{~F} 0)$ were used in test 2 , corresponding to the mean vocal fold size values (table 1 ). Two prephonatory glottal half-widths were considered: $g_{0}=0.2$ and 0.5 $\mathrm{mm}$. 

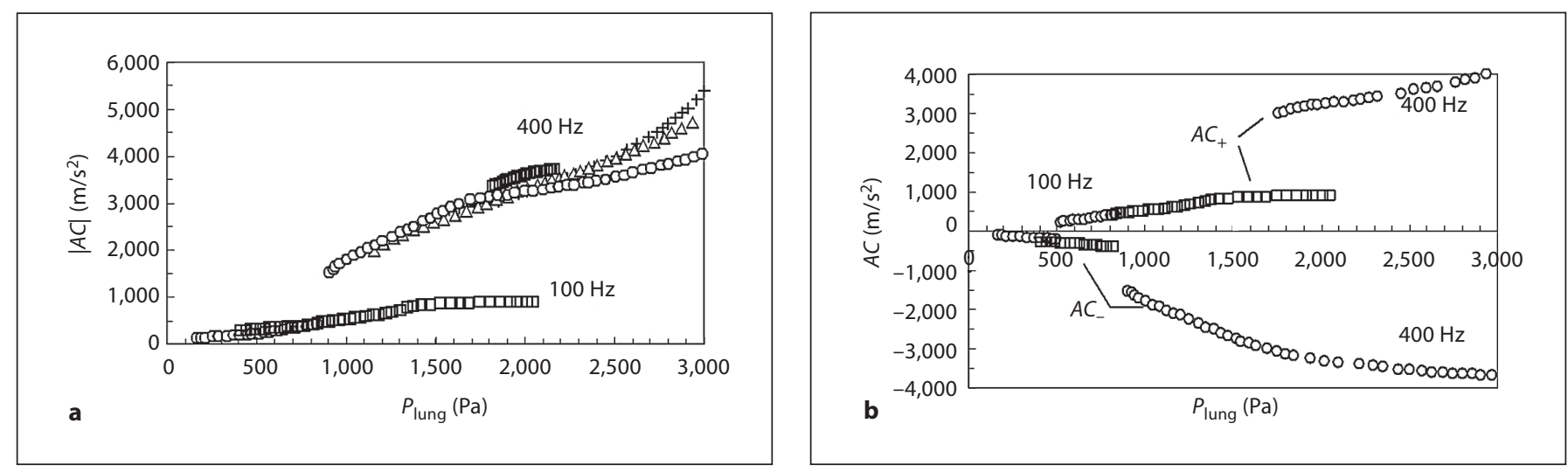

Fig. 2. a Maximum amplitude of acceleration $|A C|$. b Maximum positive $A C_{+}$and negative $A C_{-}$amplitudes of acceleration versus $P_{\text {lung }}$ for $F 0 \cong 100$ and $400 \mathrm{~Hz}$ and prephonatory glottal half-widths $g_{0}=0.2-0.5 \mathrm{~mm}(\bigcirc$ : $\left.g_{0}=0.2 \mathrm{~mm} ; \triangle: g_{0}=0.3 \mathrm{~mm} ;: g_{0}=0.4 \mathrm{~mm} ; \square: g_{0}=0.5 \mathrm{~mm}\right)$.

\section{Results}

\section{Test 1}

Figure 2 shows the $A C$ values as a function of $P_{\text {lung }}$ for $F 0 \cong 100$ and $400 \mathrm{~Hz}$, and $g_{0}=0.2-0.5 \mathrm{~mm}$. All curves begin at the phonation threshold $P_{\text {th }}$, and end either at the phonation instability threshold, or at the $P_{\text {lung }}$ and $Q$ values set as the limits (i.e., $3 \mathrm{kPa}$ and $0.8 \mathrm{l} / \mathrm{s}$, respectively).

It can be seen that the absolute value $|A C|$ increased with $P_{\text {lung }}$ (fig. 2a). For the lower fundamental frequency $(100 \mathrm{~Hz})$ and the smallest prephonatory glottal half-width $g_{0}$, the $|A C|$ was only about $110 \mathrm{~m} / \mathrm{s}^{2}$ at the $P_{\text {th }}$ and reached a plateau value of $|A C| \cong 900 \mathrm{~m} / \mathrm{s}^{2}$ at higher $P_{\text {lung }}$ and $g_{0}$ values. The $|A C|$ values were markedly higher for the higher $F 0(400 \mathrm{~Hz})$ than for the lower F0: the lowest $|A C|$ was about $1,520 \mathrm{~m} / \mathrm{s}^{2}$ for the smallest $g_{0}$ near the $P_{\text {th }}$, whereas the highest value reached $5,400 \mathrm{~m} / \mathrm{s}^{2}$ at the maximum $P_{\text {lung }}$ and $g_{0}=0.4 \mathrm{~mm}$.

In general, for low $P_{\text {lung }}$ values the maximum amplitudes of acceleration were encountered during the impact phase of the vocal fold motion. Here the acceleration was negative and the absolute value $|A C|$ was given by the $A C_{-}$ values for deceleration (regime 1). However, for high $P_{\text {lung }}$ values the maximum amplitudes of acceleration were sometimes reached during the open phase of the glottal cycle, and thus the $|A C|$ values were determined by $A C_{+}$ for acceleration (regime 2). The formation of $|A C|$ with respect to $P_{\text {lung }}$ can be seen in figure $2 \mathrm{~b}$. For $F 0 \cong 100 \mathrm{~Hz}$ the change between the regimes occurred at $P_{\text {lung }} \sim 500$ Pa for $g_{0}=0.2 \mathrm{~mm}$, and at $P_{\text {lung }} \sim 850 \mathrm{~Pa}$ for $g_{0}=0.5 \mathrm{~mm}$. For $F 0 \cong 400 \mathrm{~Hz}$ and $g_{0}=0.2 \mathrm{~mm}$ the change in regimes occurred near $P_{\text {lung }}=1,700 \mathrm{~Pa}$. For higher $P_{\text {lung }}$ values the

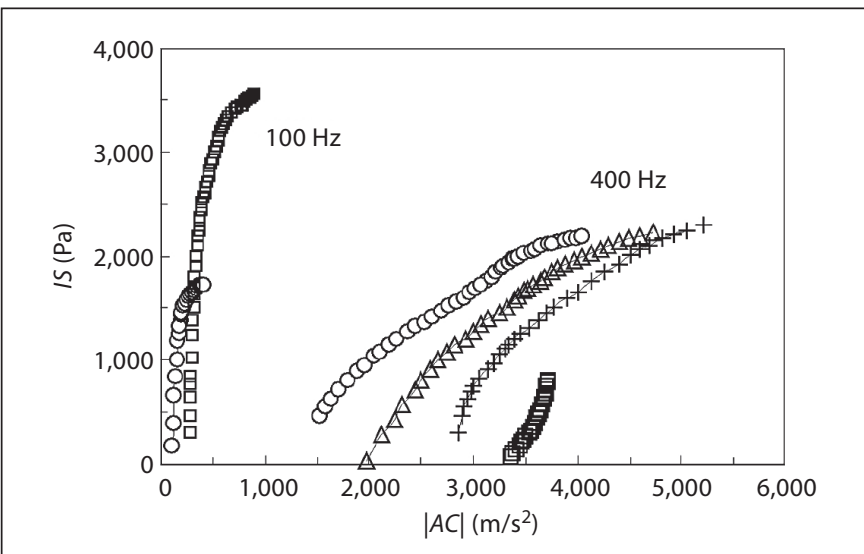

Fig. 3. Maximum impact stress $I S$ versus maximum amplitude of acceleration $|A C|$ for $F 0 \cong 100$ and $400 \mathrm{~Hz}$ and prephonatory glottal half-widths $g_{0}=0.2-0.5 \mathrm{~mm}\left(\bigcirc: g_{0}=0.2 \mathrm{~mm} ; \triangle: g_{0}=0.3 \mathrm{~mm}\right.$; $\left.+: g_{0}=0.4 \mathrm{~mm} ; \square: g_{0}=0.5 \mathrm{~mm}\right)$. For clarity, only cases $g_{0}=0.2$ and $0.5 \mathrm{~mm}$ are shown for $F 0 \cong 100 \mathrm{~Hz}$.

$A C_{+}$and $A C_{-}$values are comparable, nearly mirroring each other (fig. 2b).

Figure 3 shows $I S$ versus $|A C|$ in test 1 . It can be seen that at low $F 0(100 \mathrm{~Hz}), I S$ increased much more than $A C$, whereas at high $F 0(400 \mathrm{~Hz})$ and especially at wider prephonatory glottal half-width $g_{0}, A C$ increased more than $I S$. The maximum $A C$ value increased about 5 times when F0 increased from 100 to $400 \mathrm{~Hz}$, whereas the maximum $I S$ value reached its maximum at the low $F 0$ values. The maximum IS values were found within the range of about $1.7-3.5 \mathrm{kPa}$. 


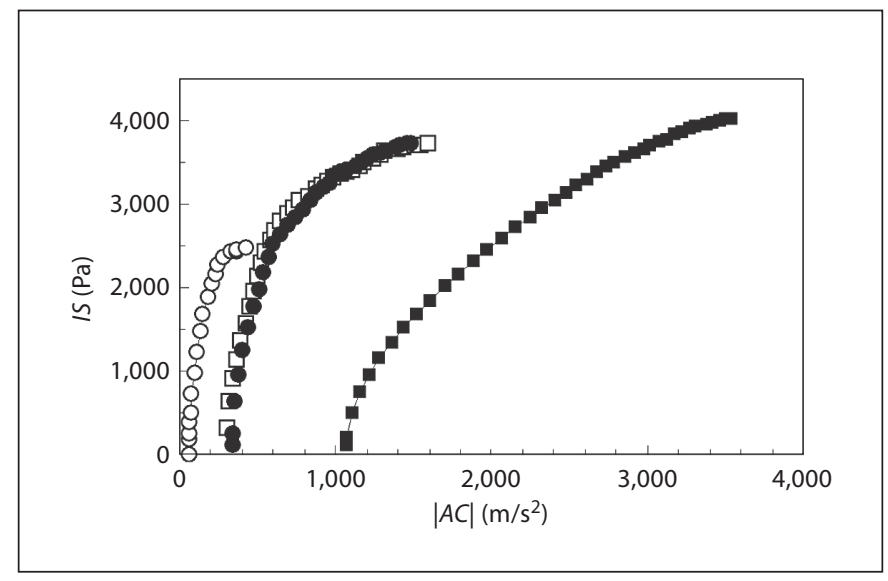

Fig. 4. Maximum impact stress IS versus maximum amplitude of acceleration $|A C|$ for bass ( $O$ :SFF, $\bullet: 2 \times$ SFF) and soprano $(\square: S F F, \square: 2 \times$ SFF) and for prephonatory glottal half-width $g_{0}=0.2 \mathrm{~mm}$.

\section{Test 2}

Figure 4 compares the $I S$ and $A C$ results for the vocal fold size values reported by Larsson and Hertegård [31]. For bass, the doubling of $F 0(2 \times$ SFF data $)$ resulted in about 1.5 times higher maximum IS values and 3.6 times higher maximum $A C$ values. For soprano, the doubling of $F 0$ resulted in about 1.1 times higher IS values and 2.2 times higher $A C$ values. It is interesting that the results for bass with double F0 $(2 \times \mathrm{SFF})$ and soprano $(\mathrm{SFF})$ were very similar even if in this case the size and total mass of the vocal fold for bass were significantly higher than for soprano (table 1). Probably, the main reason is the nearly identical fundamental frequency. Apparently, the size and mass of the vocal folds influenced the $I S$ and $A C$ values of the model much less than the FO.

Figure 5 shows the changes of IS by increasing the $P_{\text {lung }}$ values for the test 2 input data. The results are qualitatively similar to those in the previous study [30]: IS increases rapidly above $P_{\text {th }}$ and then reaches a plateau for higher $P_{\text {lung }}$ values corresponding to the plateau for the vibration amplitude (not shown here, see Horáček et al. [30]). For lower $P_{\text {lung }}$ the IS decreases with the prephonatory glottal gap, for higher $P_{\text {lung }}$ values the opposite is true; see figure 5 for bass and soprano SFF.

For the input parameters in test 2, the maximum IS and $A C$ values were found at about $4 \mathrm{kPa}$ and $3,550 \mathrm{~m} / \mathrm{s}^{2}$, respectively, both for soprano with the double fundamental frequency $F 0 \cong 378 \mathrm{~Hz}$.

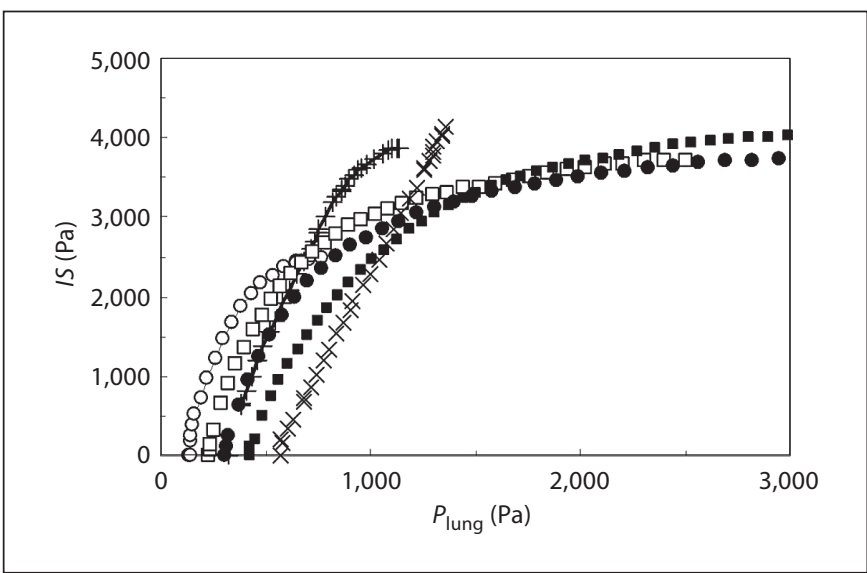

Fig. 5. Maximum impact stress $I S$ versus lung pressure $P_{\text {lung }}$ for bass and prephonatory glottal half-widths $g_{0}=0.2 \mathrm{~mm}(\bigcirc$ : SFF; ๑: $2 \times \mathrm{SFF})$ and $g_{0}=0.5 \mathrm{~mm}(+: \mathrm{SFF})$ and for soprano and $g_{0}=0.2 \mathrm{~mm}(\square: \mathrm{SFF} ; \mathbf{\square}: 2 \times \mathrm{SFF})$ and $g_{0}=0.5 \mathrm{~mm}(\times: \mathrm{SFF})$.

\section{Discussion}

\section{Comparison of Computed Results with Data from the} Literature

The results for maximum IS and $A C$ obtained in this study $\left(1.7-4 \mathrm{kPa}\right.$ and $\left.900-5,400 \mathrm{~m} / \mathrm{s}^{2}\right)$ are in a relatively good agreement with the values found in earlier computer modeling and experimental studies on excised canine larynges and human subjects (table 2). The differences appear to be caused mainly by a different range of input-controlled parameters (e.g. $P_{\text {lung }}, g_{0}, F 0$, material constants) and different measurement techniques used in the various studies.

The relationships between IS and the other parameters found here correspond to the earlier observations for canine hemilarynges [13] as well as to the recent finite element computations [12]: IS was higher at higher $P_{\text {lung }}$ values and the relationship between $I S$ and $P_{\text {lung }}$ was not linear as the $I S$ increased very fast near $P_{\text {th }}$. The $I S$ values for the input data in test 1 were the same or somewhat lower for higher fundamental frequencies, whereas for the input data in test 2 the maximum IS increased with FO similarly as in the study [13]. This may be explained by the medial reduction of the vocal fold cross-section during pitch increase which was incorporated in test 2 , based on the relationship of the data of Titze et al. [19] and Hollien and Curtis [48].

Jiang and Titze [13] reported an inverse relationship between IS and $g_{0}$. According to the earlier study by Horáček et al. [30] as well as the results presented here in 
Table 2. Comparison of the computed maximum impact stress $I S$ and maximum acceleration $A C$ in the vocal folds with the values found by various authors

\begin{tabular}{cll}
\hline & Reference & Note \\
\hline $\begin{array}{cl}\text { Max IS, kPa } \\
0.5-5\end{array}$ & Jiang and Titze [13] & canine larynges \\
$0.31-2.67$ & Jiang et al. [24] & canine larynges \\
$0.33-5.34$ & Verdolini et al. [43] & canine larynges \\
$1-5$ & Reed et al. [46] & human subjects \\
$0.4-3.2$ & Verdolini et al. [45] & human subject \\
4.5 & Gunter [10] & finite element model \\
$2-6$ & Tao et al. [11, 12] & finite element model \\
$1.7-4$ & present study & numerical simulation \\
Max $A C, \mathrm{~m} / \mathrm{s}^{2}$ & Titze [22] & \\
$500-5,000$ & Jiang et al. [24] & theory - estimated $(F 0=100-300 \mathrm{~Hz})$ \\
$909-14,700$ & Schubert et al. [25] & canine larynges \\
$750-1,500$ & Larsson and Hertegård [26] & human - estimated from velocity $(F 0=120-242 \mathrm{~Hz})$ \\
$282-923$ & Schade et al. [27] & human - estimated from velocity $(F 0=103-224 \mathrm{~Hz})$ \\
$565-2,500$ & Doellinger et al. [28] & human - estimated from velocity $(F 0=150-400 \mathrm{~Hz})$ \\
-580 to +620 & Doellinger and Berry [44] & human hemilaryngs $(F 0=115-140 \mathrm{~Hz})$ \\
-360 to +320 & Boessenecker et al. [47] & human hemilaryngs $(F 0=100-141 \mathrm{~Hz})$ \\
$320 \pm 140$ & present study & numerical simulation $(F 0=100-400 \mathrm{~Hz})$ \\
$900-5,400$ & &
\end{tabular}

test 2 , the relation between $I S$ and $g_{0}$ is ultimately determined by the $P_{\text {lung }}$ and $g_{0}$ values and, thus, by the phonation type. According to Jiang et al. [24], IS and $A C$ increased with $P_{\text {lung }}\left(P_{\text {sub }}\right)$, the maximum $A C$ always occurred during impact and the relationship between IS and $A C$ was estimated by a linear function. Our results did not confirm the findings of Jiang et al. [24]: particularly at the higher $P_{\text {lung }}$ values, the maximum amplitudes of acceleration were sometimes reached in the open phase of the glottis (fig. 2b) and the linear relation between IS and $A C$ was not generally valid (fig. 3,4 ).

\section{Considerations about Possible Detrimental Mechanisms}

The results obtained here suggest that the impact stress is more dependent on the prephonatory glottal width than on the fundamental frequency. The acceleration values, in turn, substantially increase with FO. The inertial forces, invoked by the vocal fold acceleration, may be understood as a source of additional, dynamic stress, which is present for the duration of the whole vocal fold oscillation cycle and is superimposed on the impact stress when the vocal folds collide. Thus, it is tempting to hypothesize that since $F 0$ is about twice as high in females as in males, the additional dynamic stress caused by the acceleration could be responsible for nodules and other vocal fold traumas occurring more frequently in females than males. However, the fact that females have a higher prevalence of vocal nodules compared to males is not necessarily related to acceleration. Since a higher $F 0$ as such naturally implies more cycles during a given time of voice production, the number of impacts and thus the impact (fatigue) loading is also higher.

The Hertz theory for two-dimensional elastic contact of cylindrical bodies suggests that the highest material loading due to principal shear stress $\tau_{\max }=0.3$ IS is below the contact surface at the depth $D=0.78 \varsigma_{\max }$, where $\varsigma_{\max }$ is the maximum half-width of the contact area [18]. In our case, following the vocal fold deformation shown in figure 1 , we can roughly estimate the maximum half-width of the contact area as $2 \varsigma_{\max }=L / 3$, where $L$ is the considered vocal fold thickness. Taking $L=6.8 \mathrm{~mm}$ as in test 1 , we receive a rough estimate for the maximum of the shear stress at the depth $D=0.88 \mathrm{~mm}$ below the vocal fold surface. For the thicknesses $L$ considered in test 2 , the depth of maximum shear stress would be $0.71 \mathrm{~mm}$ below the surface for bass and $0.44 \mathrm{~mm}$ for soprano. This roughly also corresponds to the modeling results by Tao and Jiang [12], where the highest magnitudes for both normal and shear stresses were found $1 \mathrm{~mm}$ below the surface of the finite element model. 
The effect of the maximum acceleration may relate approximately to the effect of the impact stress. The normal stress caused by acceleration of the tissue in the depth $D$ can be estimated as $\sigma_{\text {norm }}=d \rho_{h}|A C|$. For $d=0.88 \mathrm{~mm}$, $\rho_{h}=1,020 \mathrm{~kg} / \mathrm{m}^{3}$ and the maximum calculated acceleration $|A C|=5.4 \mathrm{kPa}$ we obtain the maximum normal stress $\sigma_{\text {norm }}=4.85 \mathrm{kPa}$, which is a comparable magnitude with the maximum value of the IS estimated. However, more information on the material and fatigue properties of the vocal fold tissue is required to further judge which forces and stress components are the most detrimental to the tissue during voice production.

\section{Conclusions}

An aeroelastic model with the Hertz model of impacts was used to study the magnitudes of impact stress IS and acceleration $A C$ in relation to lung pressure $P_{\text {lung }}$, fundamental frequency $F 0$ and prephonatory glottal half-width $g_{0}$ values corresponding to normal speech.

Maximum IS values of about $4 \mathrm{kPa}$ were obtained and $A C$ maximum reached about $5,400 \mathrm{~m} / \mathrm{s}^{2}$. These results are in line with experimental data reported in the literature. For high $F 0$ the maximum stress caused by inertial forces (proportional to $A C$ ) was calculated to be comparable with the magnitude of impact stress.
The maximum acceleration and deceleration values within an oscillation period had similar magnitudes in most of the cases studied, but at higher $P_{\text {lung }}$ values $A C$ reached maximum values during the glottal open phase. This suggests that considerable tissue loading may occur also during glottal open phase and not only due to the impact stress in closure.

Both $I S$ and $A C$ increased with $P_{\text {lung. }}$. IS appeared to be more dependent on prephonatory glottal width than on FO. IS could thus be particularly affected by phonation type. Acceleration, on the other hand, increased rapidly with F0. Further studies are warranted to investigate the hypotheses, that (a) the acceleration in addition to the impact stress is responsible for nodules and other vocal fold traumas occurring more frequently in females than males, and that (b) exceedingly high acceleration could cause vascular lesions on the top surface of the vocal folds where the impact stress is zero.

\section{Acknowledgements}

The research was supported by the Grant Agency of the Czech Republic by project No. 101/08/1155 'Computer and physical modelling of vibroacoustic properties of human vocal tract for optimization of voice quality', by grant No. 106139 'Biomechanical study on the traumatizing mechanisms in vocal fold vibration' awarded by the Academy of Finland, and by the COST Action 2103 'Advanced voice function assessment'.

\section{References}

1 Vilkman E: Occupational safety and health aspects of voice and speech professions. Folia Phoniatr Logop 2004;56:220-253.

$\checkmark 2$ Russel A, Oates J, Greenwood KM: Prevalence of voice problems in teachers. J Voice 1998; 12:467-479.

-3 Rantala L, Vilkman E: Relationship between subjective voice complaints and acoustic parameters in female teachers' voices. J Voice 1999; 13:484-495.

4 Titze IR: Physiologic and acoustic differences between male and female voices. J Acoust Soc Am 1989;4:1699-1707.

5 Titze IR: Principles of Voice Production. Englewood Cliffs, Prentice-Hall, 1994.

6 Virolainen E, Tuohimaa P, Aitasalo K, Kyttä J, Vanharanta-Hiltunen R: Steroid hormone receptors in laryngeal carcinoma. Otolaryngol Head Neck Surg 1986;94:512-517.

-7 Newman SR, Butler J, Hammond EH, Gray SD: Preliminary report on hormone receptors in the human vocal fold. J Voice 2000;14: $72-81$.
8 Titze IR: Mechanical stress in phonation. J Voice 1994;8:99-105.

$\checkmark 9$ Gunter HE: A mechanical model of vocalfold collision with high spatial and temporal resolution. J Acoust Soc Am 2003;113:9941000.

10 Gunter HE: Modeling mechanical stresses as a factor in the etiology of benign vocal fold lesions. J Biomech 2004;37:1119-1124.

11 Tao C, Jiang JJ, Zhang Y: Simulation of vocal fold impact pressures with a self-oscillating finite-element model. J Acoust Soc Am 2006; 119:3987-3994

12 Tao C, Jiang J: Mechanical stress during phonation in a self-oscillating finite-element vocal fold model. J Biomech 2007;40:21912198.

13 Jiang J, Titze I: Measurement of vocal fold intraglottal stress and impact stress. J Voice 1994;8:132-144.
14 Mäki E, Niemi HM, Lundén S, Laukkanen AM: F0, SPL and vocal fatigue in a vocally loading test. Proc 25th World Congr Int Assoc Logop Phoniatr, Montreal, 2001. CDROM.

15 Berry DA, Montequin D, Tayama N: Highspeed digital imaging of the medial surface of the vocal folds. J Acoust Soc Am 2001;110: 2539-2547.

16 Gray SD: Basement membrane zone injury in vocal nodules; in Gauffin J, Hammarberg B (eds): Vocal Fold Physiology: Acoustic, Perceptual, and Physiological Aspects of Voice Mechanisms. San Diego, Singular Publishing Group, 1991, pp 22-28.

17 Hochman I, Hillman RE, Sataloff RT, Zeitels SM: Ectasias and varices of the vocal fold: clearing the striking zone. Ann Otol Rhinol Laryngol 1999;108:10-16.

18 Johnson KL: Contact Mechanics. Cambridge, Cambridge University Press, 1989.

-19 Titze IR, Švec JG, Popolo PS: Vocal dose measures: quantifying accumulated vibration exposure in vocal fold tissues. J Speech Lang Hear Res 2003;46:919-932. 
20 Hirano M: Clinical Examination of Voice. Wien, Springer, 1981.

-21 Sonninen A, Laukkanen AM: Hypothesis of whiplike motion as a possible traumatizing mechanism in vocal fold vibration. Folia Phoniatr Logop 2003;55:189-198.

-22 Titze IR: Toward occupational safety criteria for vocalization. Logoped Phoniatr Vocol 1999;24:49-54.

23 Griffin MJ: Handbook of Human Vibration. New York, Academic Press, 1990.

24 Jiang JJ, Shah AG, Hess MH, Verdolini K, Banzali FM Jr, Hanson DG: Vocal fold impact stress analysis. J Voice 2001;15:4-14.

25 Schubert S, Hoppe U, Döllinger M, Lohscheller J, Eysholdt U: High-precision measurement of the vocal fold length and vibratory amplitudes. Laryngoscope 2002;112: 1043-1049.

-26 Larsson H, Hertegård S: Calibration of highspeed imaging by laser triangulation. Logoped Phoniatr Vocol 2004;29:154-161.

27 Schade G, Kirchhof T, Hess M: Geschwindigkeitsmessung der Stimmlippenbewegung. Folia Phoniatr Logop 2005;57:202215.

28 Doellinger M, Berry DA, Berke GS: A quantitative study of the medial surface dynamics of an in vivo canine vocal fold during phonation. Laryngoscope 2005;115:1646-1654.

-29 Horáček J, Šidlof P, Švec JG: Numerical simulation of self-oscillations of human vocal folds with Hertz model of impact forces. J Fluid Struct 2005;20:853-869.

30 Horáček J, Laukkanen AM, Šidlof P: Estimation of impact stress using an aeroelastic model of voice production. Logoped Phoniatr Vocol 2007;32:185-192.
Larsson H, Hertegård S: Vocal fold dimensions in professional opera singers as measured by means of laser triangulation. J Voice 2008;22:734-739.

32 Horáček J, Laukkanen AM, Šidlof P: Physiological values obtained from aeroelastic model of human vocal folds vibration; in $\mathrm{Zo}$ lotarev I (ed): Proceedings of the XIth Seminar Interaction of Dynamic Systems with Surroundings and Systems with Feedbacks, 2004, Prague. Prague, Institute of Thermomechanics, Academy of Sciences, 2004, pp 31-42.

33 Berry DA, Herzel H, Titze IR, Krischer K: Interpretation of biomechanical simulations of normal and chaotic vocal fold oscillations with empirical eigenfunctions. J Acoust Soc Am 1994;95:3595-3604.

34 Berry DA, Titze IR: Normal modes in a continuum model of vocal fold tissues. J Acoust Soc Am 1996;100:3345-3354.

35 De Vries MP, Schutte HK, Verkerke GJ: Determination of parameters for lumped parameter models of the vocal folds using a finite-element method approach. J Acoust Soc Am 1999; 106:3620-3628.

36 Horáček J, Švec JG: Aeroelastic model of vocal-fold-shaped vibrating element for studying the phonation threshold. J Fluid Struct 2002; 16:927-951.

Švec JG, Horáček J, Šram F, Veselý J: Resonance properties of the vocal folds: in vivo laryngoscopic investigation of the externally excited laryngeal vibrations. J Acoust Soc Am 2000;108:1397-1407.

38 Isshiki N: Regulatory mechanism of voice intensity variation. J Speech Hear Res 1964; $7: 17-29$.
39 Baken RJ, Orlikoff R: Clinical Measurement of Speech and Voice, ed 2. San Diego, Singular Thomson, 2000.

40 Jiang J, Titze IR: A methodological study of hemilaryngeal phonation. Laryngoscope 1993; 103:872-882.

41 Leino T, Laukkanen AM, Ilomäki I, Mäki E: Assessment of vocal capacity of Finnish university students. Folia Phoniatr Logop 2008; 60:199-209.

42 Berry DA, Verdolini K, Chan RW, Titze IR: Indications of an optimum glottal width in vocal production. NCVS Status Progress Rep 1998;12:33-41.

43 Verdolini K, Chan R, Titze IR, Hess M, Bierhals W: Correspondence of electroglottographic closed quotient to vocal fold impact stress in excised canine larynges. J Voice 1998;12:184-202.

44 Doellinger M, Berry DA: Visualization and quantification of the medial surface dynamics of an excised human vocal fold during phonation. J Voice 2006;20:401-413.

- 45 Verdolini K, Hess MM, Titze IR, Bierhals W, Gross M: Investigation of vocal fold impact stress in human subjects. J Voice 1999;13: 184-202.

46 Reed CG, Doherty ET, Shipp T: Direct measurement of vocal fold medial forces. Am Speech Hear Assoc Rep 1992;34:131(A).

47 Boessenecker A, Berry DA, Lohscheller J, Eysholdt U, Doellinger M: Mucosal wave properties of a human vocal fold. Acta Acust United Acust 2007;93:815-823.

-48 Hollien H, Curtis J: A laminagraphic study of vocal pitch. J Speech Hear Res 1960;3:361371. 